\title{
Hour Times Picomole Per Liter Per Kilogram
}

National Cancer Institute

\section{Source}

National Cancer Institute. Hour Times Picomole Per Liter Per Kilogram. NCI Thesaurus.

Code C112311.

Hours times picomoles per liter, divided by kilograms. 